\title{
Assessing Old and New Individual Study Desks
}

\author{
Holt Zaugg \\ Brigham Young University, holt_zaugg@byu.edu \\ C. Jeffrey Belliston \\ Brigham Young University, jeffrey_belliston@byu.edu
}

Follow this and additional works at: https://scholarsarchive.byu.edu/facpub

Part of the Library and Information Science Commons

\section{Original Publication Citation}

Zaugg, H. and Belliston, C.J. (2020), Assessing old and new individual study desks, Performance Measurement and Metrics, Vol. ahead-of-print No. ahead-of-print. https://doi.org/10.1108/

PMM-12-2019-0062

\section{BYU ScholarsArchive Citation}

Zaugg, Holt and Belliston, C. Jeffrey, "Assessing Old and New Individual Study Desks" (2020). Faculty Publications. 4170.

https://scholarsarchive.byu.edu/facpub/4170

This Peer-Reviewed Article is brought to you for free and open access by BYU ScholarsArchive. It has been accepted for inclusion in Faculty Publications by an authorized administrator of BYU ScholarsArchive. For more information, please contact ellen_amatangelo@byu.edu. 


\section{Performance Measurement and $\mathrm{A}$}

\section{Assessing Old and New Individual Study Desks}

\begin{tabular}{|r|l|}
\hline Journal: & Performance Measurement and Metrics \\
\hline Manuscript ID & PMM-12-2019-0062.R1 \\
\hline Manuscript Type: & Research Paper \\
\hline Keywords: & $\begin{array}{l}\text { study spaces, study carrels, study desks, study experience, learning } \\
\text { experience, prototyping }\end{array}$ \\
\hline
\end{tabular}

SCHOLARONE $^{\text {m }}$

Manuscripts 


\section{Assessing Old and New Individual Study Desks}

\section{Introduction}

Changes to academic library spaces require input from primary users to develop the spaces they want and need (Hall and Kapa, 2015; Loder, 2000; Walton, 2006; Zhang and Maddison, 2016). These spaces include open spaces with tables, group study spaces, innovation spaces, and individual study spaces. Each has advantages and drawbacks. For example, Loder (2000) indicates that tables provide the opportunity to spread out materials, but when used by more than one student, tables make it difficult to define an individual's workspace. While individual study desks (since many students do not understand the term carrel, we call them "individual study desks," or ISDs) define a student's workspace, there is little room for spreading out materials, nor is there opportunity to add amenities (e.g. electrical and USB outlets) that aid studying students.

Since their inception, ISDs typically resembled a wood box on stilts with a confined writing surface and a shelf. Chairs were normally wood built more to last than to be comfortable. As far back as the 1960s there were calls to improve ISD design so they would have an excellent study lamp, contain a larger desk with considerable writing surface, and have a comfortable seat (Sommer and Peterson, 1967). These changes could enable ISDs to better fit students' learning and research needs.

\section{Background}

In 1976, the first of two additions to the CCC opened. The addition included the purchase of more than 400 ISDs and accompanying wooden chairs. These ISDs were distributed across the library's five public floors.

In early 2014, a faculty member who teaches a Technology 312: Innovation Bootcamp course asked if the library had a project that the students could do as part of the course. The library suggested developing a replacement for the library's nearly forty-year-old ISDs. The Innovation Bootcamp students applied the USERS model to approach the problem (Skaggs et al., 2012). USERS stands for

- U-Understand (Observe/Experience/Inquire)

- S-Shape (Organize/Simplify/Clarify)

- E-Explore (Question/Compare/Combine)

- R-Refine (Visualize/Validate/Iterate)

- S-Share

Based on surveys, observations, and informal focus groups, three different teams from the class developed and shared solutions with library administrators. Using the common themes identified by the Innovation Bootcamp teams (more space, privacy, shelving, electrical and USB outlets, lighting, a footrest, a reading stand, a whiteboard, and a comfortable chair), a design 
team that included library and university physical facilities personnel developed two prototype ISDs.

Each prototype included desired features (e.g., LED vs. fluorescent lighting or a small vs. large shelf). The prototypes were placed side-by-side in a high traffic area of the library, and students passing by (convenience sample) were invited to sit in each and provide feedback via an online survey. The ISD prototypes were then placed on four different floors over the course of a month for students to use. Students using the ISD prototypes were asked to complete a paper survey about their experience.

Based on the input from these two surveys, the design team made changes to the alpha prototypes and retested the resulting beta prototypes in the same way. The results of the beta surveys resulted in a final design for the new ISDs. Since 2016, the library began replacing the old ISDs with batches of new ISDs. At the time of this study, the library had replaced about half of the old ISDs with new ISDs. It was determined that a follow-up study was needed to answer the following questions:

1. In what ways are the new ISDs better than the old ISDs?

2. What, if any, difference do the new ISDs make to the students using them?

This paper reports on the results of the follow-up study.

\section{Method}

Two parallel surveys used a convenience sample and had identical questions except for questions asking about use patterns and amenities specific to the new ISDs (see Appendix A). Students were invited to participate in each survey via a QR code or a URL link shown on flyers placed in each ISD for one week. The QR code and URL links corresponded to the survey matching the ISD (e.g., links on flyers in new ISDs connected to the new ISD survey). Library personnel reviewed each ISD daily to replace any flyers that had been taken or moved. As an incentive to participate, those completing a survey could enter into a draw for one of five $\$ 10$ cash rewards. As this study examined and compared use patterns of the two ISDs, having the same student use and comment on both types of ISD was considered an advantage rather than a bias.

The surveys included three open-ended questions to understand why students studied where they did, what improvements to the desk itself were needed, and what was otherwise needed to improve the students' experience when working at an ISD. Two student researchers independently coded all comments from the three open-ended questions using the list of themes developed from responses (see Appendix B). Researchers counted how often comments were independently assigned to the same theme by both coders to determine the trustworthiness of coding. For example, if both coders agreed on the coding of the comment, the coding was accepted and considered trustworthy. However, if coders did not agree on how the comment should be coded, they discussed reasons why it should or should not be coded to a certain theme until they reached a consensus on how the comment should be coded. 
All assessment procedures were approved by the university's IRB committee.

\section{Findings}

\section{Demographics}

Over the week that both surveys were active, a total of 1,288 responses were received (old ISD $=591$, new ISD $=697$ ). Both surveys had a gender response rate of about $60 \%$ male and $45 \%$ female (see Table 1). Sophomore and senior use of the two ISD types did not differ significantly (see Table 2). However, freshmen used old ISDs significantly more than new ISDs ( $29 \%$ vs. $23 \%$ ) while juniors used new ISDs significantly more than old ISDs ( $28 \%$ vs. $23 \%)$. The use of the old ISDs by students appears to decline as students' time at the university increases; seniors used both old and new ISDs at about the same rate. The "other" category includes students working in a university entrance program, students from neighboring universities, and those visiting the university.

[Insert Tables $1 \& 2$ about here]

Desk Use

Students used both desk types a comparable number of times weekly (see Table 3), but varied in length of stay for each visit (see Table 4). Significantly more students stayed at old ISDs for durations of 31-60 minutes or 61-90 minutes. Significantly more students stayed at new ISDs for durations of 91-120 minutes or over 120 minutes.

[Insert Tables 3 and 4 about here]

A 5-point rating scale $(1=$ not very comfortable, $5=$ very comfortable $)$ was used to examine the comfort level of each desk type. A higher, non-significant proportion of students rated the old ISDs as less comfortable than the new ISDs (see Table 5). Conversely, significantly more students rated the new ISDs as more comfortable at either the second highest or highest levels of comfort. This finding complements the previous finding as a better level of comfort encourages students to stay longer.

[Insert Table 5 about here]

\section{ISD Activities}

Users of both old and new ISDs were asked to identify all of the activities they engaged in and the degree to which they engaged in each activity (a lot, some, and rarely or never) while using an ISD. Table 6 shows the students' level of engagement for each activity by desk type.

Primary activities in the "done a lot" category for both desks included doing homework assignments, studying for exams, and academic reading. Of these activities, significantly more 
students studied for exams in new ISDs than in old ISDs $(p<0.05)$. Conversely, significantly more academic reading took place in old ISDs than in new ISDs $(p<0.05)$.

For activities in the "done some" category, significantly more students did exam study in old ISDs than in new ISDs $(p<0.05)$. Significantly more personal reading took place in new ISDs than in old ISDs $(p<0.05)$. No activities "done rarely or never" had significant differences between the ISD types, but activities that ranked lower in the "done a lot" category (i.e., gaming, sleeping, personal reading, praying, and meditating or pondering) were activities that most students engaged in rarely or never.

[Insert Table 6 about here]

Secondary uses for the desk (used by less than $50 \%$ of the students but more than $20 \%$ ) included more personal activities such as personal watching or listening, meditating or pondering, praying, and sleeping.

New ISDs include a whiteboard on the long sidewall of the desk. Over $90 \%$ of students used the whiteboard, with most using it to solve equations, map out strategies, summarize class notes/readings, and/or create writing outlines (see Table 7).

[Insert Table 7 about here]

\section{Desk Amenities}

We also examined student preference for the specific amenities of the new ISDs. Amenities preferred by $70 \%$ or more of students included (in order of preference) electrical outlets, the whiteboard, desk space, a movable footrest, and under-the-shelf lighting.

\section{Open-Ended Survey Comments}

Where possible the same themes for comparing responses for the three questions were used. However, some themes were unique to particular questions. Themes and their descriptions are in Appendix B.

Reasons for study. Among students' primary reasons for choosing a new ISD were privacy and the ability to focus. Those using old ISDs indicated that ISD location, typically in low traffic areas allowing more privacy, was more important than using a new ISD. Students also adopted the new ISD as their personal space; similar to findings in other studies (Bodaghi and Zainab, 2013). Typical student responses included:

... I really like having my own little study space to focus and work on homework. I think that I am more productive in this type of environment because it is less distracting than having a lot of people coming and going and that gives me enough space to just plug into what I'm doing. 
I can focus better here because of the walls. I'm not distracted by other people, I can focus on my work.

Unique to those choosing a new ISD were comments on amenities (e.g., whiteboard and space) as key reasons for the choice. Most comments indicated that these amenities facilitated studying and concentration. Typical comments were:

The extended desk space is super nice, I like to lay out all my books, computer, and notebooks without feeling cluttered. The light is really nice too and the personal outlet for charging your phone or computer. And since I usually spend a few hours studying for a big exam at these desks, the swivel office chair is so much more comfortable than a wooden chair.

The white boards are awesome for scratch work and save me from using a lot of paper. The chairs are more comfortable than any of the wooden chairs in the library. Lots of desk space and easy access to electrical outlets.

Improved desk and experience. Comments referring to what could improve the desk or the student's experience using the desk took a bit of an ironic twist. Those using an old ISD indicated that they wanted a better chair, power outlets, and a whiteboard - amenities that would make the old ISDs similar to the new ISDs.

One indication of the success of the new ISDs was the more than $44 \%$ of comments positively mentioned one or more amenities of the new desks. Users of new ISDs wanted to ensure that dry erase markers and erasers were available for the whiteboards. The two most common comments from new ISD users were requests for more new ISDs and statements that no improvements were needed. For example:

Just have more of them. It is a bummer when they are all filled because then I have to sit at a desk which usually leads to me getting distracted by friends and my studying is less effective.

\section{Discussion}

These findings indicate that, while the number of visits each week is similar between the two desk types, significantly more students using old ISDs stay for shorter periods of time and significantly more students using new ISDs stay for longer periods of time.

When we combine the totals for the "done a lot" and "done some" categories, it is apparent that both ISDs are primarily used for academic activities. Almost 100\% of students used the ISDs for studying for exams and completing homework assignments. More than $75 \%$ 
of students indicated that they read, watched, or listened to academic material while at an ISD. These findings support the idea that ISD $\underline{s}$ are generally used for academic pursuits typical of the focuser persona (i.e., a student who wishes to study alone and be focused on a given activity without interruptions; Zaugg and Rackham, 2016; Zaugg, 2017). These results support findings that students use ISDs primarily for academic and personal activities (Loder, 2000; Walton, 2006).

\section{Conclusion}

The success of the new ISDs is attributed to an effective and iterative design process based on feedback and prototyping. Using feedback from users of old ISDs, Innovation Bootcamp class members created concepts for new ISDs. Prototypes helped to refine these ISD concepts into a new ISD that students use more, value more, and better meet their needs. 


\section{References}

Bodaghi, N.B. and Zainab, A.N. (2013), "My carrel, my second home: inclusion and the sense of belonging among visually impaired students in an academic library", Malaysian Journal of Library \& Information Science, Vol. 18 No. 1, pp. 39-54.

Hall, K. and Kapa, D. (2015), "Silent and independent: student use of academic library study space", The Canadian Journal of Library and Information Practice and Research, Vol. 10 No. 1, pp. 1-38.

Loder, M.W. (2000), "Seating patterns and improvements in a small college library: a case study”, College \& Undergraduate Libraries, Vol. 7 No. 2, pp. 83-94.

Skaggs, P., Fry, R. and Wright, G. (2012), "Creating a mindset for innovation”, Journal of Strategic Innovation and Sustainability, Vol. 7 No. 3, pp. 95-99.

Sommer, R. and Peterson, P. (1967), "Study carrels re-examined", College \& Research Libraries, Vol. 28 No. 4, pp. 263-265, 272.

Walton, G. (2006), “Learners' demands and expectations for space in a university library: outcomes from a survey at Loughborough University", New Review of Academic Librarianship, Vol. 12 No. 2, pp. 133-149.

Zaugg, H. (2017), "Using persona descriptions to inform library space design", in Hines, S.S. and Crowe, K.M. (Eds.), The Future of Library Space, Emerald, United Kingdom, pp. $335-358$.

Zaugg, H. and Rackham, S. (2016), "Identification and development of patron personas for an academic library”, Performance Measurement and Metrics, Vol. 17, No. 2, pp. 124-133.

Zhang, L. and Maddison, T. (2016), "Involving users in the library space planning: a case study of a branch library in a research university", Chinese American Librarian Association Occasional Paper Series, No. 13, pp. 1-11. 


\section{New ISD}

\section{Appendix A: Surveys for New and Old ISDs}

Q1 We are examining how students use our new individual study desks. We invite you to take a few minutes and complete our short survey to help us understand how these individual study desks are working as a study space for you and what we can do to improve them. If you start the survey, you may refuse to answer any question or you may stop answering the survey at any time. However, we would appreciate you completing the survey. Those completing the survey have the chance to enter a draw for one of five $\$ 10$ Cougar Cash incentives. This study is being conducted by a research team led by BBB, Assessment Librarian (801-422-4718 or BBB@,AAA.edu). If you have any questions or concerns, please contact him. You may also contact AAA's Office of Research \& Creative Activities if you have any concerns about this survey.

Yes, I will participate

No, I do not want to participate.

Q2 What is your gender?

Male

Female

Q3 What is your status at AAA?

Freshman (year 1)

Sophomore (year 2)

Junior (year 3)

Senior (year 4)

Super-senior (year 5+)

Graduate student

Other (please specify)

Q4 How many times per week do you typically use an individual study desk like this one?

$$
1-5
$$

$6-10$

$11+$

Q5 For what length of time do you stay during a typical visit?

0-30 minutes

31-60 minutes

61-90 minutes

91-120 minutes

Over 120 minutes 
Q6 How physically comfortable is studying in this individual study desk?

$(1=$ not very comfortable, $5=$ very comfortable $)$

\begin{tabular}{|l|l|l|l|l|l|}
\hline & Not very comfortable & 2 & 3 & 4 & Very comfortable \\
\hline ISD physical comfort & & & & & \\
\hline
\end{tabular}

Q7 If an individual study desk like the one you are in was not available, where would you go to study?

Another type of individual study desk

A table

A lounge chair

A bar desk spot

A group study room

Other (please specify)

I would leave the library and study elsewhere.

Q8 Please drag and drop each activity into the appropriate box to best describe what you typically do in an individual study desk.

Studying for exams

Working on homework assignments

Academic reading

Personal reading

Academic watching/listening

Personal watching/listening

Gaming

Sleeping

Praying

Meditating or pondering

Other (please specify)

\begin{tabular}{l|l|l} 
I do this a lot & I do this some of the time & I rarely or never do this \\
\hline & &
\end{tabular}

Q9 What do you do on the white board?

I do not use the white board

Solve equations

Map out strategies 
Create outlines for writing

Summarize class notes/readings

Write motivational quotes

Drawing/doodling

Other (please specify)

Q10 Which of the following best describes you?

I typically try to get an individual study desk in the same general area of the library.

I use individual study desks in various locations depending on my mood.

Q11 What features of the study desks do you use? Only check the things you use.

Light under shelf

Electric plug

Desk extension

USB Plugs

Moveable footrest

Shelf

Q12 What features of these individual study desks do you like?

Color

Size of side walls

Desk space

Shelf

Location

Q13 How can we make individual study desks like this one better?

Q14 In what ways can we improve your experience using the individual study desks like this one?

Q15 Think back to where you studied before we had these new individual study desks.

Comparing your study experience with this individual study desk and your previous study space, why do you choose to study here? 
Q16 As our way of saying thanks for filling out the survey, we are having a draw where five people who completed the survey will have $\$ 10$ Cougar Cash deposited to their account. If you would like to enter the draw please provide your name, email, and net ID below.

Name

Email

Net ID

\section{Old ISD}

Q1 We are examining how students use our individual study desks. We invite you to take a few minutes and complete our short survey to help us understand how these individual study desks are working as a study space for you. If you start the survey, you may refuse to answer any question or you may stop answering the survey at any time. However, we would appreciate you completing the survey. Those completing the survey have the chance to enter a draw for one of five $\$ 10$ Cougar Cash incentives. This study is being conducted by a research team led by BBB, Assessment Librarian (801-422-4718 or BBB@,AAA.edu). If you have any questions or concerns, please contact him. You may also contact AAA's Office of Research \& Creative Activities if you have any concerns about this survey.

Yes, I will participate

No, I do not want to participate.

Q2 What is your gender?

Male

Female

Q3 What is your status at AAA?

Freshman (year 1)

Sophomore (year 2)

Junior (year 3)

Senior (year 4)

Super-senior (year $5+$ )

Graduate student

Other (please specify)

Q4 How many times per week do you typically use an individual study desk like this one? $1-5$

$6-10$

$11+$ 
Q5 For what length of time do you stay during a typical visit?

0-30 minutes

31-60 minutes

61-90 minutes

91-120 minutes

Over 120 minutes

Q6 How physically comfortable is studying in this individual study desk? $(1=$ not very comfortable, $5=$ very comfortable $)$

\begin{tabular}{|l|l|l|l|l|l|}
\hline & Not very comfortable & 2 & 3 & 4 & Very comfortable \\
\hline ISD physical comfort & & & & & \\
\hline
\end{tabular}

Q7 If an individual study desk like the one you are in was not available, where would you go to study?

Another type of individual study desk

A table

A lounge chair

A bar desk spot

A group study room

Other (please specify)

I would leave the library and study elsewhere.

Q8 Please drag and drop each activity into the appropriate box to best describe what you typically do in an individual study desk.

Studying for exams

Working on homework assignments

Academic reading

Personal reading

Academic watching/listening

Personal watching/listening

Gaming

Sleeping

Praying

Meditating or pondering

Other (please specify)

I do this a lot

I do this some of the time

I rarely or never do this 
Q12 In what ways can we improve your experience using individual study desks like this one?

Q10 What features of these individual study desks do you like? Only check the things you like. Color

Size of side walls

Desk space

Shelf

Location

Q11 In what ways could we make individual study desks like this one better?

Q13 Think back to where you have studied in the library. Comparing your study experience with this individual study desk and your previous study space, why do you choose to study here?

Q14 As our way of saying thanks for filling out the survey, we are having a draw where five people who completed the survey will have $\$ 10$ Cougar Cash deposited to their account. If you would like to enter the draw please provide your name, email, and net ID below. Name

Email

Net ID 


\section{Appendix B: Themes for Open-Ended Questions}

In what ways could we make individual study desks like this one better?

\begin{tabular}{ll}
\hline Theme & Description \\
\hline Amenities: Chair & Asks for or specifically refers to chair or seating \\
Amenities: Desk light & Asks for or specifically refers to desk light or lighting \\
Amenities: Footrest & Asks for or specifically refers to footrest \\
Amenities: Other & Asks for or refers to a specific amenity of the ISD \\
Amenities: Outlets & Asks for or specifically refers to outlets, USB or plugs \\
Amenities: Size & Asks for or specifically refers to room or size of desk \\
Amenities: Walls & Asks for or specifically refers to walls of desk, including wall color \\
Amenities: White board & Asks for or specifically refers to white board, erasers, or pens \\
Cleaner & Comments that desks need to be cleaned more often \\
Location/orientation & Indicates a general or specific place that the ISD may be located \\
More new desks & Specifically asks for more new ISDs \\
OK & Indicates that the desk is fine the way it is \\
Other & Any comment that does not fit within the other categories \\
Snacks/food & Comments on the ability to eat food or snacks at an ISD or the \\
Surrounding area & problems it may cause \\
& Comments on the area or amenities around the desk but not the \\
& desk itself \\
\hline
\end{tabular}

In what ways can we improve your experience using individual study desks like this one?

\begin{tabular}{ll}
\hline Theme & Description \\
\hline Amenities: Chair & Asks for or specifically refers to chair or seating \\
Amenities: Desk light & Asks for or specifically refers to desk light or lighting \\
Amenities: Footrest & Asks for or specifically refers to footrest \\
Amenities: Other & Asks for or refers to a specific amenity of the ISD \\
Amenities: Outlets & Asks for or specifically refers to outlets, USB or plugs \\
Amenities: Size & Asks for or specifically refers to room or size of desk \\
Amenities: Walls & Asks for or specifically refers to walls of desk, including wall color \\
Amenities: White board & Asks for or specifically refers to white board, erasers, or pens \\
Cleaner & Comments that desks need to be cleaned more often \\
Direction of desk & Indicates a preference for a desk to face a certain direction \\
Location/orientation & Indicates a general or specific place that the ISD may be located \\
More new desks & Would like there to be more ISDs \\
Nothing & There is nothing to improve or no comment \\
OK & Indicates that the desk is fine the way it is \\
Other & Any comment that does not fit within the other categories \\
Snacks/food & Comments on the ability to eat food or snacks at an ISD or the \\
& problems it may cause \\
Surrounding area & Comments on the area or amenities around the desk but not the \\
\hline
\end{tabular}


Think back to where you have studied in the library. Comparing your study experience with this individual study desk and your previous study space, why do you choose to study here?

\begin{tabular}{ll}
\hline Theme & Description \\
\hline Amenities: Chair & Discusses or specifically refers to chair or seating \\
Amenities: Desk light & Discusses or specifically refers to desk light or lighting \\
Amenities: Footrest & Discusses or specifically refers to footrest \\
Amenities: Outlets & Discusses or specifically refers to outlets, USB or plugs \\
Amenities: Size & Discusses or specifically refers to room or size of desk \\
Amenities: Walls & Discusses or specifically refers to walls of desk, including color \\
Amenities: White board & Discusses or specifically refers to white board \\
Amenities: Other & Discusses or refers to a specific amenity of the ISD \\
Accessibility & Comments on help with learning disability \\
Availability/convenience & $\begin{array}{l}\text { Comments on availability of use or unavailability of preferred } \\
\text { space }\end{array}$ \\
Focus & Comments on ability to focus on activity for a variety of reasons \\
Location & Comments on physical location, ambiance of things around it, and \\
Mental health & access \\
Privacy & Refers to improving feelings about studying \\
Type of study space & Comments on avoiding interruptions, distractions, or noise \\
Other & They study there because it is a desk for use just by the person \\
\end{tabular}


Table 1

Total respondents by gender.

\begin{tabular}{lcccc}
\hline Gender & \multicolumn{2}{c}{ Old } & \multicolumn{2}{c}{ New } \\
\hline Male & $n$ & $\%$ & $n$ & $\%$ \\
Female & 341 & 58 & 420 & 60 \\
\hline Total & 248 & 42 & 279 & 40 \\
\hline
\end{tabular}

Table 2

Percentage of participant desk usage by student status.

\begin{tabular}{llll}
\hline Status & Old & New & $p$-value \\
\hline Freshman (year 1) & $\mathbf{2 9 \%}$ & $\mathbf{2 3 \%}$ & $\mathbf{0 . 0 1 8}$ \\
Sophomore (year 2) & $25 \%$ & $26 \%$ & \\
Junior (year 3) & $\mathbf{2 3 \%}$ & $\mathbf{2 8 \%}$ & $\mathbf{0 . 0 1 6}$ \\
Senior (year 4) & $14 \%$ & $15 \%$ & \\
Super-senior (year 5+) & $5 \%$ & $5 \%$ & \\
Graduate student & $3 \%$ & $2 \%$ & \\
Other & $1 \%$ & $0.3 \%$ & \\
\hline
\end{tabular}

Note: Boldface indicates a significant difference between groups.

Table 3

Percentage of participant desk usage by frequency of use.

\begin{tabular}{lll}
\hline Times used/week & Old & New \\
\hline $1-5$ & $76 \%$ & $79 \%$ \\
$6-10$ & $18 \%$ & $17 \%$ \\
$11+$ & $6 \%$ & $4 \%$ \\
\hline
\end{tabular}

Table 4

Percentage of participant desk usage by length of stay.

\begin{tabular}{llll}
\hline Length of stay $(\mathrm{min})$ & Old & New & $p$-value \\
\hline $0-30$ & $2 \%$ & $1 \%$ & \\
$31-60$ & $\mathbf{2 1 \%}$ & $\mathbf{1 3 \%}$ & $<\mathbf{0 . 0 0 1}$ \\
$61-90$ & $\mathbf{4 2 \%}$ & $\mathbf{3 5 \%}$ & $\mathbf{0 . 0 2 0}$ \\
$91-120$ & $\mathbf{2 2 \%}$ & $\mathbf{3 0 \%}$ & $<\mathbf{0 . 0 0 1}$ \\
$120+$ & $\mathbf{1 3 \%}$ & $\mathbf{2 0 \%}$ & $\mathbf{0 . 0 0 2}$ \\
\hline
\end{tabular}

Note: Boldface indicates significant difference between groups. 
Table 5

Percentage of participant desk usage by physical comfort rating.

\begin{tabular}{llll}
\hline Level of physical comfort & Old & New & $p$-value \\
\hline 1 (not very comfortable) & $6 \%$ & $0.3 \%$ & \\
2 & $29 \%$ & $2 \%$ & \\
3 & $37 \%$ & $10 \%$ & \\
4 & $\mathbf{2 3 \%}$ & $\mathbf{4 4 \%}$ & $<\mathbf{0 . 0 0 1}$ \\
5 (very comfortable) & $\mathbf{5 \%}$ & $\mathbf{4 4 \%}$ & $<\mathbf{0 . 0 0 1}$ \\
\hline
\end{tabular}

Table 6

Percentage of participant desk usage by activity frequency.

\begin{tabular}{lllllll}
\hline & \multicolumn{2}{c}{ Done a lot } & \multicolumn{2}{c}{ Done some } & \multicolumn{2}{c}{ Done rarely or never } \\
ISD activity & Old & New & Old & New & Old & New \\
\hline Studying for exams & $\mathbf{7 5 \%}$ & $\mathbf{8 4 \%}$ & $\mathbf{1 9 \%}$ & $\mathbf{1 3 \%}$ & $3 \%$ & $2 \%$ \\
Working on homework assignments & $86 \%$ & $90 \%$ & $10 \%$ & $8 \%$ & $2 \%$ & $1 \%$ \\
Academic reading & $\mathbf{5 7 \%}$ & $\mathbf{5 2 \%}$ & $30 \%$ & $33 \%$ & $8 \%$ & $9 \%$ \\
Personal reading & $\mathbf{7 \%}$ & $5 \%$ & $\mathbf{1 9 \%}$ & $\mathbf{2 6 \%}$ & $65 \%$ & $62 \%$ \\
Academic watching/listening & $34 \%$ & $35 \%$ & $42 \%$ & $43 \%$ & $16 \%$ & $14 \%$ \\
Personal watching/listening & $11 \%$ & $7 \%$ & $37 \%$ & $40 \%$ & $44 \%$ & $46 \%$ \\
Gaming & $0.3 \%$ & $1 \%$ & $8 \%$ & $5 \%$ & $84 \%$ & $87 \%$ \\
Sleeping & $4 \%$ & $2 \%$ & $24 \%$ & $20 \%$ & $66 \%$ & $70 \%$ \\
Praying & $5 \%$ & $7 \%$ & $30 \%$ & $29 \%$ & $56 \%$ & $55 \%$ \\
Meditating or pondering & $7 \%$ & $6 \%$ & $34 \%$ & $37 \%$ & $51 \%$ & $51 \%$ \\
Other & $3 \%$ & $3 \%$ & $2 \%$ & $1 \%$ & $9 \%$ & $7 \%$ \\
\hline$N$ & 591 & 697 & 591 & 697 & 591 & 697 \\
\hline
\end{tabular}

Note: Boldface indicates significant difference between groups. Students could select more than one option.

Table 7

Percentage of students using new ISD whiteboards for specific tasks.

\begin{tabular}{ll}
\hline White Board Uses & $\%$ \\
\hline Solving equations & 25 \\
Mapping out strategies & 19 \\
Summarizing class notes/readings & 16 \\
Creating writing outlines & 14 \\
Drawing/doodling & 5 \\
Writing motivational quotes & 3 \\
Did not use & 9 \\
Other & 9 \\
\hline
\end{tabular}

Note: Participants could select more than one feature so percentages are not out of 100. 


\section{Assessing Old and New Individual Study Desks}

\section{Introduction}

Changes to academic library spaces require input from primary users to develop the spaces they want and need (Hall and Kapa, 2015; Loder, 2000; Walton, 2006; Zhang and Maddison, 2016). These spaces include open spaces with tables, group study spaces, innovation spaces, and individual study spaces. Each has advantages and drawbacks. For example, Loder (2000) indicates that tables provide the opportunity to spread out materials, but when used by more than one student, tables make it difficult to define an individual's workspace. While individual study desks (since many students do not understand the term carrel, we call them "individual study desks," or ISDs) define a student's workspace, there is little room for spreading out materials, nor is there opportunity to add amenities (e.g. electrical and USB outlets) that aid studying students.

Since their inception, ISDs typically resembled a wood box on stilts with a confined writing surface and a shelf. Chairs were normally wood built more to last than to be comfortable. As far back as the 1960s there were calls to improve ISD design so they would have an excellent study lamp, contain a larger desk with considerable writing surface, and have a comfortable seat (Sommer and Peterson, 1967). These changes could enable ISDs to better fit students' learning and research needs.

\section{Background}

In 1976, the first of two additions to the CCC opened. The addition included the purchase of more than 400 ISDs and accompanying wooden chairs. These ISDs were distributed across the library's five public floors.

In early 2014, a faculty member who teaches a Technology 312: Innovation Bootcamp course asked if the library had a project that the students could do as part of the course. The library suggested developing a replacement for the library's nearly forty-year-old ISDs. The Innovation Bootcamp students applied the USERS model to approach the problem (Skaggs et al., 2012). USERS stands for

- U-Understand (Observe/Experience/Inquire)

- S-Shape (Organize/Simplify/Clarify)

- E-Explore (Question/Compare/Combine)

- R-Refine (Visualize/Validate/Iterate)

- S-Share

Based on surveys, observations, and informal focus groups, three different teams from the class developed and shared solutions with library administrators. Using the common themes identified by the Innovation Bootcamp teams (more space, privacy, shelving, electrical and USB outlets, lighting, a footrest, a reading stand, a whiteboard, and a comfortable chair), a design 
team that included library and university physical facilities personnel developed two prototype ISDs.

Each prototype included desired features (e.g., LED vs. fluorescent lighting or a small vs. large shelf). The prototypes were placed side-by-side in a high traffic area of the library, and students passing by (convenience sample) were invited to sit in each and provide feedback via an online survey. The ISD prototypes were then placed on four different floors over the course of a month for students to use. Students using the ISD prototypes were asked to complete a paper survey about their experience.

Based on the input from these two surveys, the design team made changes to the alpha prototypes and retested the resulting beta prototypes in the same way. The results of the beta surveys resulted in a final design for the new ISDs. Since 2016, the library began replacing the old ISDs with batches of new ISDs. At the time of this study, the library had replaced about half of the old ISDs with new ISDs. It was determined that a follow-up study was needed to answer the following questions:

1. In what ways are the new ISDs better than the old ISDs?

2. What, if any, difference do the new ISDs make to the students using them?

This paper reports on the results of the follow-up study.

\section{Method}

Two parallel surveys used a convenience sample and had identical questions except for questions asking about use patterns and amenities specific to the new ISDs (see Appendix A). The two surveys were developed by the authors using information from other library assessments, including the original assessments done by the Innovation Bootcamp. The intent of the survey questions was to compare student use patterns of the two desks to determine if there was a difference and, if so, what was the difference between the desks. The intent of the survey was not to create a measurement tool to be used by other universities, but to examine whether changes made in this institution made a difference in student learning. While the survey was not developed or intended for broader use, other institutions may use it as a model for comparison assessments of furniture and space changes to their institution.

Students were invited to participate in each survey via a QR code or a URL link shown on flyers placed in each ISD for one week. The QR code and URL links corresponded to the survey matching the ISD (e.g., links on flyers in new ISDs connected to the new ISD survey). Library personnel reviewed each ISD daily to replace any flyers that had been taken or moved. As an incentive to participate, those completing a survey could enter into a draw for one of five $\$ 10$ cash rewards. As this study examined and compared use patterns of the two ISDs, having the same student use and comment on both types of ISD was considered an advantage rather than a bias.

The surveys included three open-ended questions to understand why students studied where they did, what improvements to the desk itself were needed, and what was otherwise 
needed to improve the students' experience when working at an ISD. Two student researchers independently coded all comments from the three open-ended questions using the list of themes developed from responses (see Appendix B). Researchers counted how often comments were independently assigned to the same theme by both coders to determine the trustworthiness of coding. For example, if both coders agreed on the coding of the comment, the coding was accepted and considered trustworthy. However, if coders did not agree on how the comment should be coded, they discussed reasons why it should or should not be coded to a certain theme until they reached a consensus on how the comment should be coded.

All assessment procedures were approved by the university's IRB committee.

\section{Demographics}

\section{Findings}

Over the week that both surveys were active, a total of 1,288 responses were received (old ISD $=591$, new ISD $=697$ ). Both surveys had a gender response rate of about $60 \%$ male and $45 \%$ female (see Table 1). Sophomore and senior use of the two ISD types did not differ significantly (see Table 2). However, freshmen used old ISDs significantly more than new ISDs ( $29 \%$ vs. $23 \%$ ) while juniors used new ISDs significantly more than old ISDs (28\% vs. $23 \%$ ). The use of the old ISDs by students appears to decline as students' time at the university increases; seniors used both old and new ISDs at about the same rate. The "other" category includes students working in a university entrance program, students from neighboring universities, and those visiting the university.

[Insert Tables $1 \& 2$ about here]

Desk Use

Students used both desk types a comparable number of times weekly (see Table 3), but varied in length of stay for each visit (see Table 4). Significantly more students stayed at old ISDs for durations of 31-60 minutes or 61-90 minutes. Significantly more students stayed at new ISDs for durations of 91-120 minutes or over 120 minutes.

[Insert Tables 3 and 4 about here]

A 5-point rating scale ( $1=$ not very comfortable, 5 = very comfortable) was used to examine the comfort level of each desk type. A higher, non-significant proportion of students rated the old ISDs as less comfortable than the new ISDs (see Table 5). Conversely, significantly more students rated the new ISDs as more comfortable at either the second highest or highest levels of comfort. This finding complements the previous finding as a better level of comfort encourages students to stay longer. 


\section{[Insert Table 5 about here]}

\section{ISD Activities}

Users of both old and new ISDs were asked to identify all of the activities they engaged in and the degree to which they engaged in each activity (a lot, some, and rarely or never) while using an ISD. Table 6 shows the students' level of engagement for each activity by desk type.

Primary activities in the "done a lot" category for both desks included doing homework assignments, studying for exams, and academic reading. Of these activities, significantly more students studied for exams in new ISDs than in old ISDs $(p<0.05)$. Conversely, significantly more academic reading took place in old ISDs than in new ISDs $(p<0.05)$.

For activities in the "done some" category, significantly more students did exam study in old ISDs than in new ISDs $(p<0.05)$. Significantly more personal reading took place in new ISDs than in old ISDs $(p<0.05)$. No activities "done rarely or never" had significant differences between the ISD types, but activities that ranked lower in the "done a lot" category (i.e., gaming, sleeping, personal reading, praying, and meditating or pondering) were activities that most students engaged in rarely or never.

[Insert Table 6 about here]

Secondary uses for the desk (used by less than $50 \%$ of the students but more than $20 \%$ ) included more personal activities such as personal watching or listening, meditating or pondering, praying, and sleeping.

New ISDs include a whiteboard on the long sidewall of the desk. Over $90 \%$ of students used the whiteboard, with most using it to solve equations, map out strategies, summarize class notes/readings, and/or create writing outlines (see Table 7).

[Insert Table 7 about here]

\section{Desk Amenities}

We also examined student preference for the specific amenities of the new ISDs. Amenities preferred by $70 \%$ or more of students included (in order of preference) electrical outlets, the whiteboard, desk space, a movable footrest, and under-the-shelf lighting.

\section{Open-Ended Survey Comments}

Where possible the same themes for comparing responses for the three questions were used. However, some themes were unique to particular questions. Themes and their descriptions are in Appendix B.

Reasons for study. Among students' primary reasons for choosing a new ISD were privacy and the ability to focus. Those using old ISDs indicated that ISD location, typically in 
low traffic areas allowing more privacy, was more important than using a new ISD. Students also adopted the new ISD as their personal space; similar to findings in other studies (Bodaghi and Zainab, 2013). Typical student responses included:

... I really like having my own little study space to focus and work on homework.

I think that I am more productive in this type of environment because it is less distracting than having a lot of people coming and going and that gives me enough space to just plug into what I'm doing.

I can focus better here because of the walls. I'm not distracted by other people, I can focus on my work.

Unique to those choosing a new ISD were comments on amenities (e.g., whiteboard and space) as key reasons for the choice. Most comments indicated that these amenities facilitated studying and concentration. Typical comments were:

The extended desk space is super nice, I like to lay out all my books, computer, and notebooks without feeling cluttered. The light is really nice too and the personal outlet for charging your phone or computer. And since I usually spend a few hours studying for a big exam at these desks, the swivel office chair is so much more comfortable than a wooden chair.

The white boards are awesome for scratch work and save me from using a lot of paper. The chairs are more comfortable than any of the wooden chairs in the library. Lots of desk space and easy access to electrical outlets.

Improved desk and experience. Comments referring to what could improve the desk or the student's experience using the desk took a bit of an ironic twist. Those using an old ISD indicated that they wanted a better chair, power outlets, and a whiteboard-amenities that would make the old ISDs similar to the new ISDs.

One indication of the success of the new ISDs was the more than $44 \%$ of comments positively mentioned one or more amenities of the new desks. Users of new ISDs wanted to ensure that dry erase markers and erasers were available for the whiteboards. The two most common comments from new ISD users were requests for more new ISDs and statements that no improvements were needed. For example:

Just have more of them. It is a bummer when they are all filled because then I have to sit at a desk which usually leads to me getting distracted by friends and my studying is less effective. 


\section{Discussion}

These findings indicate that, while the number of visits each week is similar between the two desk types, significantly more students using old ISDs stay for shorter periods of time and significantly more students using new ISDs stay for longer periods of time.

When we combine the totals for the "done a lot" and "done some" categories, it is apparent that both ISDs are primarily used for academic activities. Almost 100\% of students used the ISDs for studying for exams and completing homework assignments. More than 75\% of students indicated that they read, watched, or listened to academic material while at an ISD. These findings support the idea that ISD $\underline{s}$ are generally used for academic pursuits typical of the focuser persona (i.e., a student who wishes to study alone and be focused on a given activity without interruptions; Zaugg and Rackham, 2016; Zaugg, 2017). These results support findings that students use ISDs primarily for academic and personal activities (Loder, 2000; Walton, 2006).

\section{Conclusion}

The success of the new ISDs is attributed to an effective and iterative design process based on feedback and prototyping. Using feedback from users of old ISDs, Innovation Bootcamp class members created concepts for new ISDs. Prototypes helped to refine these ISD concepts into a new ISD that students use more, value more, and better meet their needs.

The library continues to replace all of the old ISDs, with an anticipated completion date of 2021. Additionally, the library's Assessment Office has completed and continues to evaluate other renovated spaces and altered services within the library as advocated by Zaugg (2018). This practice helps the library to know if changes made were improvements instead of just a change to something different. 


\section{References}

Bodaghi, N.B. and Zainab, A.N. (2013), "My carrel, my second home: inclusion and the sense of belonging among visually impaired students in an academic library", Malaysian Journal of Library \& Information Science, Vol. 18 No. 1, pp. 39-54.

Hall, K. and Kapa, D. (2015), "Silent and independent: student use of academic library study space", The Canadian Journal of Library and Information Practice and Research, Vol. 10 No. 1, pp. 1-38.

Loder, M.W. (2000), "Seating patterns and improvements in a small college library: a case study", College \& Undergraduate Libraries, Vol. 7 No. 2, pp. 83-94.

Skaggs, P., Fry, R. and Wright, G. (2012), “Creating a mindset for innovation”, Journal of Strategic Innovation and Sustainability, Vol. 7 No. 3, pp. 95-99.

Sommer, R. and Peterson, P. (1967), "Study carrels re-examined", College \& Research Libraries, Vol. 28 No. 4, pp. 263-265, 272.

Walton, G. (2006), “Learners' demands and expectations for space in a university library: outcomes from a survey at Loughborough University", New Review of Academic Librarianship, Vol. 12 No. 2, pp. 133-149.

Zaugg, H. (2017), "Using persona descriptions to inform library space design", in Hines, S.S. and Crowe, K.M. (Eds.), The Future of Library Space, Emerald, United Kingdom, pp. $335-358$.

Zaugg, H. (2018), "Begin Again", in Britto, M. and Kinsley, K. (Eds.), Academic Libraries and the Academy: Strategies and Approaches to Demonstrate Your Value, Impact, and Return on Investment, ACRL, Chicago, IL, pp. 137-147.

Zaugg, H. and Rackham, S. (2016), "Identification and development of patron personas for an academic library", Performance Measurement and Metrics, Vol. 17, No. 2, pp. 124-133.

Zhang, L. and Maddison, T. (2016), "Involving users in the library space planning: a case study of a branch library in a research university", Chinese American Librarian Association Occasional Paper Series, No. 13, pp. 1-11. 


\section{New ISD}

\section{Appendix A: Surveys for New and Old ISDs}

Q1 We are examining how students use our new individual study desks. We invite you to take a few minutes and complete our short survey to help us understand how these individual study desks are working as a study space for you and what we can do to improve them. If you start the survey, you may refuse to answer any question or you may stop answering the survey at any time. However, we would appreciate you completing the survey. Those completing the survey have the chance to enter a draw for one of five \$10 Cougar Cash incentives. This study is being conducted by a research team led by BBB, Assessment Librarian (801-422-4718 or

BBB@,AAA.edu). If you have any questions or concerns, please contact him. You may also contact AAA's Office of Research \& Creative Activities if you have any concerns about this survey.

Yes, I will participate

No, I do not want to participate.

Q2 What is your gender?

Male

Female

Q3 What is your status at AAA?

Freshman (year 1)

Sophomore (year 2)

Junior (year 3)

Senior (year 4)

Super-senior (year 5+)

Graduate student

Other (please specify)

Q4 How many times per week do you typically use an individual study desk like this one?

1-5

$6-10$

$11+$

Q5 For what length of time do you stay during a typical visit?

0-30 minutes

31-60 minutes

61-90 minutes

91-120 minutes

Over 120 minutes 
Q6 How physically comfortable is studying in this individual study desk?

$(1=$ not very comfortable, $5=$ very comfortable $)$

\begin{tabular}{|l|l|l|l|l|l|}
\hline & Not very comfortable & 2 & 3 & 4 & Very comfortable \\
\hline ISD physical comfort & & & & & \\
\hline
\end{tabular}

Q7 If an individual study desk like the one you are in was not available, where would you go to study?

Another type of individual study desk

A table

A lounge chair

A bar desk spot

A group study room

Other (please specify)

I would leave the library and study elsewhere.

Q8 Please drag and drop each activity into the appropriate box to best describe what you typically do in an individual study desk.

Studying for exams

Working on homework assignments

Academic reading

Personal reading

Academic watching/listening

Personal watching/listening

Gaming

Sleeping

Praying

Meditating or pondering

Other (please specify)

\begin{tabular}{l|l|l} 
I do this a lot & I do this some of the time & I rarely or never do this \\
\hline & &
\end{tabular}

Q9 What do you do on the white board?

I do not use the white board

Solve equations

Map out strategies 
Create outlines for writing

Summarize class notes/readings

Write motivational quotes

Drawing/doodling

Other (please specify)

Q10 Which of the following best describes you?

I typically try to get an individual study desk in the same general area of the library.

I use individual study desks in various locations depending on my mood.

Q11 What features of the study desks do you use? Only check the things you use.

Light under shelf

Electric plug

Desk extension

USB Plugs

Moveable footrest

Shelf

Q12 What features of these individual study desks do you like?

Color

Size of side walls

Desk space

Shelf

Location

Q13 How can we make individual study desks like this one better?

Q14 In what ways can we improve your experience using the individual study desks like this one?

Q15 Think back to where you studied before we had these new individual study desks.

Comparing your study experience with this individual study desk and your previous study space, why do you choose to study here? 
Q16 As our way of saying thanks for filling out the survey, we are having a draw where five people who completed the survey will have \$10 Cougar Cash deposited to their account. If you would like to enter the draw please provide your name, email, and net ID below.

Name

Email

Net ID

\section{Old ISD}

Q1 We are examining how students use our individual study desks. We invite you to take a few minutes and complete our short survey to help us understand how these individual study desks are working as a study space for you. If you start the survey, you may refuse to answer any question or you may stop answering the survey at any time. However, we would appreciate you completing the survey. Those completing the survey have the chance to enter a draw for one of five $\$ 10$ Cougar Cash incentives. This study is being conducted by a research team led by BBB, Assessment Librarian (801-422-4718 or BBB@AAA.edu). If you have any questions or concerns, please contact him. You may also contact AAA's Office of Research \& Creative Activities if you have any concerns about this survey.

Yes, I will participate

No, I do not want to participate.

Q2 What is your gender?

Male

Female

Q3 What is your status at AAA?

Freshman (year 1)

Sophomore (year 2)

Junior (year 3)

Senior (year 4)

Super-senior (year 5+)

Graduate student

Other (please specify)

Q4 How many times per week do you typically use an individual study desk like this one? $1-5$

$6-10$

$11+$ 
Q5 For what length of time do you stay during a typical visit?

0-30 minutes

31-60 minutes

61-90 minutes

91-120 minutes

Over 120 minutes

Q6 How physically comfortable is studying in this individual study desk? $(1=$ not very comfortable, $5=$ very comfortable $)$

\begin{tabular}{|l|l|l|l|l|l|}
\hline & Not very comfortable & 2 & 3 & 4 & Very comfortable \\
\hline ISD physical comfort & & & & & \\
\hline
\end{tabular}

Q7 If an individual study desk like the one you are in was not available, where would you go to study?

Another type of individual study desk

A table

A lounge chair

A bar desk spot

A group study room

Other (please specify)

I would leave the library and study elsewhere.

Q8 Please drag and drop each activity into the appropriate box to best describe what you typically do in an individual study desk.

Studying for exams

Working on homework assignments

Academic reading

Personal reading

Academic watching/listening

Personal watching/listening

Gaming

Sleeping

Praying

Meditating or pondering

Other (please specify)

I do this a lot

I do this some of the time

I rarely or never do this 
Q9 Which of the following best describes you?

I typically try to get an individual study desk in the same general area of the library. I use individual study desks in various locations depending on my mood.

Q10 What features of these individual study desks do you like? Only check the things you like. Color

Size of side walls

Desk space

Shelf

Location

Q11 In what ways could we make individual study desks like this one better?

Q12 In what ways can we improve your experience using individual study desks like this one?

Q13 Think back to where you have studied in the library. Comparing your study experience with this individual study desk and your previous study space, why do you choose to study here?

Q14 As our way of saying thanks for filling out the survey, we are having a draw where five people who completed the survey will have $\$ 10$ Cougar Cash deposited to their account. If you would like to enter the draw please provide your name, email, and net ID below. Name

Email

Net ID 


\section{Appendix B: Themes for Open-Ended Questions}

In what ways could we make individual study desks like this one better?

\begin{tabular}{ll}
\hline Theme & Description \\
\hline Amenities: Chair & Asks for or specifically refers to chair or seating \\
Amenities: Desk light & Asks for or specifically refers to desk light or lighting \\
Amenities: Footrest & Asks for or specifically refers to footrest \\
Amenities: Other & Asks for or refers to a specific amenity of the ISD \\
Amenities: Outlets & Asks for or specifically refers to outlets, USB or plugs \\
Amenities: Size & Asks for or specifically refers to room or size of desk \\
Amenities: Walls & Asks for or specifically refers to walls of desk, including wall color \\
Amenities: White board & Asks for or specifically refers to white board, erasers, or pens \\
Cleaner & Comments that desks need to be cleaned more often \\
Location/orientation & Indicates a general or specific place that the ISD may be located \\
More new desks & Specifically asks for more new ISDs \\
OK & Indicates that the desk is fine the way it is \\
Other & Any comment that does not fit within the other categories \\
Snacks/food & Comments on the ability to eat food or snacks at an ISD or the \\
Surrounding area & problems it may cause \\
& Comments on the area or amenities around the desk but not the \\
& desk itself \\
\hline
\end{tabular}

In what ways can we improve your experience using individual study desks like this one?

\begin{tabular}{ll}
\hline Theme & Description \\
\hline Amenities: Chair & Asks for or specifically refers to chair or seating \\
Amenities: Desk light & Asks for or specifically refers to desk light or lighting \\
Amenities: Footrest & Asks for or specifically refers to footrest \\
Amenities: Other & Asks for or refers to a specific amenity of the ISD \\
Amenities: Outlets & Asks for or specifically refers to outlets, USB or plugs \\
Amenities: Size & Asks for or specifically refers to room or size of desk \\
Amenities: Walls & Asks for or specifically refers to walls of desk, including wall color \\
Amenities: White board & Asks for or specifically refers to white board, erasers, or pens \\
Cleaner & Comments that desks need to be cleaned more often \\
Direction of desk & Indicates a preference for a desk to face a certain direction \\
Location/orientation & Indicates a general or specific place that the ISD may be located \\
More new desks & Would like there to be more ISDs \\
Nothing & There is nothing to improve or no comment \\
OK & Indicates that the desk is fine the way it is \\
Other & Any comment that does not fit within the other categories \\
Snacks/food & Comments on the ability to eat food or snacks at an ISD or the \\
Surrounding area & problems it may cause \\
\hline
\end{tabular}


Think back to where you have studied in the library. Comparing your study experience with this individual study desk and your previous study space, why do you choose to study here?

\begin{tabular}{ll}
\hline Theme & Description \\
\hline Amenities: Chair & Discusses or specifically refers to chair or seating \\
Amenities: Desk light & Discusses or specifically refers to desk light or lighting \\
Amenities: Footrest & Discusses or specifically refers to footrest \\
Amenities: Outlets & Discusses or specifically refers to outlets, USB or plugs \\
Amenities: Size & Discusses or specifically refers to room or size of desk \\
Amenities: Walls & Discusses or specifically refers to walls of desk, including color \\
Amenities: White board & Discusses or specifically refers to white board \\
Amenities: Other & Discusses or refers to a specific amenity of the ISD \\
Accessibility & Comments on help with learning disability \\
Availability/convenience & $\begin{array}{l}\text { Comments on availability of use or unavailability of preferred } \\
\text { space }\end{array}$ \\
Focus & Comments on ability to focus on activity for a variety of reasons \\
Location & Comments on physical location, ambiance of things around it, and \\
Mental health & access \\
Privacy & Refers to improving feelings about studying \\
Type of study space & Comments on avoiding interruptions, distractions, or noise \\
Other & $\begin{array}{l}\text { They study there because it is a desk for use just by the person } \\
\text { Any comment that does not fit within the other categories or is not } \\
\end{array}$
\end{tabular}

